\title{
Hemşirelik ve Ebelik Öğrencilerinin Ailede Kadına Yönelik Şiddete İlişkin Tutumlar1 ${ }^{1}$
}

\author{
DOI: $10.26466 /$ opus.611843
}

\author{
$*$ \\ Berna Aktaș $^{*}$ - Fadime Kaya ${ }^{* *}$ - Nihal Bostancı Daştan ${ }^{* * *}$ \\ * Arş. Gör., Kafkas Üniversitesi, Sağlık Bilimleri Fakültesi, Merkez / Kars / Türkiye \\ E-Posta: brnaktas57@gmail.com \\ ORCID: 0000-0002-8722-8299 \\ ** Dr. Öğr. Üyesi, Kafkas Üniversitesi, Sağlık Bilimleri Fakültesi, Merkez / Kars / Türkiye \\ E-Posta: fadimee36@hotmail.com ORCID: 0000-0002-7352-0387 \\ *** Doç. Dr., Kafkas Üniversitesi, Sağllk Bilimleri Fakültesi, Merkez / Kars / Türkiye \\ E-Posta: nbdastan@gmail.com \\ ORCID: $\quad$ 0000-0001-5580-4960
}

\section{Öz}

Bu çalışma, hemşirelik ve ebelik öğrencilerinin ailede kadına yönelik şiddete ilişkin tutumların belirlemek amacıyla yapılmıştır. Kesitsel olan araştırmanın evrenini Kafkas Üniversitesi Sağlık Bilimleri Fakültesi 2016-2017 yılındaki tüm hemşirelik ve ebelik öğrencileri oluşturmuştur (N=859). Araştırmada örneklem seçilmemiş ve öğrencilerin 522'sinden geçerli sonuç elde edilmiştir (\% 60.8). Veriler bir anket formu ve Şiddete İlişkin Tutum Ölçeği ile toplanmıştır. Veri analizinde tanımlayıcı analizlerin yanı sira Mann Whitney $U$, Kruskal Wallis testleri ve Spearman's rho Korelasyon analizi

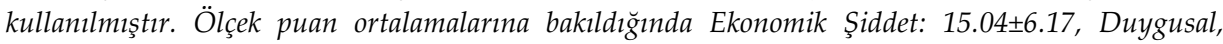

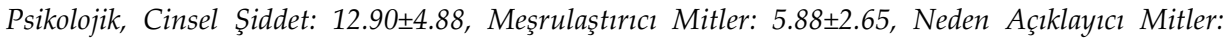
7.03 \pm 2.53 , Toplam Şiddet Puanı: 40.86 \pm 12.25 olarak belirlenmiştir. Toplam şiddet puan ortalaması ile yaş arasında pozitif bir ilişki olduğu $(r=0.088 ; p=0.046)$, erkeklerin $k ı z(U=13.603 ; p=0.000)$, hemşirelik bölümü öğrencilerinin ebelik bölümü $(U=5.347 ; p=0.000)$ öğrencilerine göre puan ortalamalarının istatistiksel olarak anlamlı derecede daha yüksek olduğu belirlenmiştir. Öğrencilerin şiddete yönelik puan ortalamalarının genel olarak düşük, şiddet tutumlarının geleneksellikten az ve şiddet tutumlarının çă̆daş görüşe yaklaştığı görülmektedir

Anahtar Kelimeler: Hemşirelik, ebelik, öğrenci, kadına yönelik şiddet, tutum

\footnotetext{
${ }^{1}$ Bu çalışmanın özeti, 20-23.11.2018'de V. Uluslararası IX. Ulusal Psikiyatri Hemşireliği Kongresi'nde sözel sunulmuş ve kongre kitapçığında özet bildiri olarak yayınlanmıştır
} 


\title{
The Attitudes of Nursing and Midwifery Students toward Domestic Violence against Women
}

\begin{abstract}
The study was conducted for the purpose of determining the attitudes of nursing and midwifery students toward domestic violence against women. Target population of the cross-sectional study consisted of all nursing and midwifery students receiving education in Kafkas University Faculty of Health Sciences in the 2016-2017 academic year $(N=859)$. In the study, no sample was selected and valid results were obtained from 522 of the students (60.8\%). The data were collected with a questionnaire form and the Attitude toward Violence Scale. In the analysis of the data; Mann Whitney U, Kruskal Wallis tests and Spearman's rho Correlation analysis were used besides descriptive analyses. The scale score averages were found as follows; Economic Violence: 15.04 \pm 6.17 , Emotional, Psychological, Sexual Violence: $12.90 \pm 4.88$, Legalizing Myths: 5.88 2.65, Reason Explaining Myths: $7.03 \pm 2.53$ and the Total Violence Score: $40.86 \pm 12.25$. It was determined that there was a positive correlation between the total violence score average and age $(r=0.088 ; p=0.046)$ and the scores were higher in male students than female students $(U=13.603 ; p=0.000)$ and in nursing students than midwifery students $(U=5.347 ; p=0.000)$ in a statistically significant way. It was seen that the students' violence-related score averages were generally lower and their attitudes toward violence were fewer from traditionality and closer to the modern view.
\end{abstract}

Keywords: Nursing, midwifery, student, violence against women, attitude 


\section{Giriş}

İnsanlık tarihi kadar eski ve en önemli sorunlardan biri olan şiddet, kuşaktan kuşağa bulaşıcı hastalık gibi sorun çözme biçimi olarak aktarılarak sinsi bir şekilde ilerlemektedir (Baysan Arabacı, 2014). Kadına yönelik şiddet, Dünya Sağlık Örgütü (DSÖ)'ne göre büyük bir halk sağlığı sorunu olup hem kamusal alanda hem de özel hayatta sıklığ her geçen gün artmaktadır (Baysan Arabacl, 2014; Karakurt, Smith ve Whiting, 2014; Çelik ve diğ. 2015; WHO, 2017; Kurt ve diğ. 2018; Mermer ve Öztürk Derin, 2018; Uyar, Yıldırım Öztürk ve Şahin, 2018). Kadına yönelik şiddet eylemleri; tecavüz, ensest ve diğer cinsel şiddet türleri, fiziksel şiddet, ekonomik şiddet ve duygusal istismardır (Baysan Arabac1, 2014; Karakurt, Smith ve Whiting, 2014; Kurt ve diğ. 2018; Uyar, Yıldırım Öztürk ve Şahin, 2018; Hawcroft ve diğ. 2019).

Aile için şiddet; "ailede veya hane içinde meydana gelen her türlü cinsiyete dayalı eylem, tehdit, kuvvet veya kontrol içeren duygusal, ekonomik veya fiziksel hasara neden olan şiddet" olarak tanımlanmaktadır ve genellikle kadının eşi/partneri tarafından kadına uygulanmaktadır (Karabulutlu, 2015; Kurt ve diğ. 2018; Hawcroft ve diğ. 2019). Dünya Sağlık Örgütü'nün 2013 yılındaki, 80'den fazla ülkeden mevcut verileri kullandığı bir analiz çalışmasında, dünya genelinde kadınların yaklaşık 3'te 1'i veya \% 35'inin yaşamları boyunca fiziksel veya cinsel şiddete maruz kaldığını gösterilmiştir (Özcan ve Kırca, 2017; WHO, 2017). Kadına yönelik şiddetle ilgili Türkiye'de nedenlerine ve önlenmesine dair pek çok başarılı yasa, eylem planı ve farkındalık çalışmaları yapılmasına rağmen bu durum çok yerleşmiş, üstü kapalı bir sorun olarak 21. yüzyıla taşınan en önemli sorunlardan birini oluşturmaktadır (Baysan Arabacl, 2014; Özcan ve Kırca, 2017; TUİK, 2018). Bunun en önemli nedeni, Türkiye'nin sosyo-kültürel yapısındaki şiddeti meşrulaştıran, normalleştiren, öğreten, şiddete yönelik duyarsızlaşma oluşturan sosyal değerler ve heteroseksist-ataerkil yapıdaki cinsiyet eşitsizliğine göre erkeğin kadının önünde olmasıdır. 2014 yılında kır-kent yerleşim alanlarını temsil eden 12 coğrafi bölgedeki 15-59 yaşlar arasındaki kadınları kapsayan (7462 kadın) “Türkiye'de Kadına Yönelik Aile İçi Şiddet Araştırması" sonuçlarına göre; kadınların \% 38'inin fiziksel, \% 12'sinin cinsel ve \% 44'ünün duygusal şiddete maruz kaldığ 1 belirlenmiştir (Tü- 
rkiye'de Kadına Yönelik Aile İçi Şiddet Araştırmasihttp://www.hips.hacettepe.edu.tr/KKSA-TRAnaRaporKitap26Mart.pdf). 2003 Türkiye Nüfus ve Sağlık Araştırması verilerine göre araştırmanın gerçekleştirildiği Doğu Anadolu bölgesinde bu oranın \% 45.9 kadar yükseldiği görülmektedir (Şenol ve Yıldız, 2013).

Kadına yönelik şiddet, kadınların yaşamlarında kısa ve uzun süreli etkilere neden olmaktadır. Kadına yönelik şiddet; intihar, başkasını öldürme ve morbiditenin en önemli nedenlerindendir (Baysan Arabac1, 2014; Delara, 2016; WHO, 2017; Mermer ve Derin Öztürk, 2018; Hawcroft ve diğ. 2019). Kadına yönelik şiddetin yaralanma, sakatlanma, ağrıya (Uyar, Yıldırım Öztürk ve Şahin, 2018; Hawcroft ve diğ. 2019), istenmeyen hamileliğe, küretaja, düşüğe (Uyar, Yıldırım Öztürk ve Şahin, 2018; Hawcroft ve diğ. 2019), ölü doğuma (Uyar, Yıldırım Öztürk ve Şahin, 2018; Hawcroft ve diğ. 2019), erken doğuma (Uyar, Yıldırım Öztürk ve Şahin, 2018; Hawcroft ve diğ. 2019), düşük doğum ağırlıklı bebeklerin doğmasına (Uyar, Yıldırım Öztürk ve Şahin, 2018; Hawcroft ve diğ. 2019), hipertansiyona (Uyar, Yıldırım Öztürk ve Şahin, 2018; Hawcroft ve diğ. 2019), vajinal kanamaya (Uyar, Yıldırım Öztürk ve Şahin, 2018; Hawcroft ve diğ. 2019), jinekolojik sorunlara ve HIV dahil cinsel yolla bulaşan enfeksiyonlara (Uyar, Yıldırım Öztürk ve Şahin, 2018; Cavanaugh ve diğ. 2019; Gonzalez-Guarda ve diğ. 2019; Hawcroft ve diğ. 2019), öz-saygının azalmasına (Del Río Ferres, Megías ve Expósito, 2013; Karakurt, Smith ve Whiting, 2014; Delara 2016; Uyar, Y1ldırım Öztürk ve Şahin, 2018), emosyonel iyilikte azalmaya (Del Río Ferres, Megías ve Expósito, 2013), depresyona (Baysan Arabac1, 2014; Karakurt, Smith ve Whiting, 2014; Delara, 2016; Uyar, Yıldırım Öztürk ve Şahin, 2018; Hawcroft ve diğ. 2019), travma sonrası stres bozukluğuna (Karakurt, Smith ve Whiting, 2014; Delara, 2016; Uyar, Yıldırım Öztürk ve Şahin, 2018), anksiyeteye (Delara, 2016; Uyar, Yıldırım Öztürk ve Şahin, 2018; Hawcroft ve diğ. 2019), uyku bozukluğuna (Baysan Arabac1, 2014; Uyar, Yıldırım Öztürk ve Şahin, 2018; Hawcroft ve diğ. 2019), hırpalanmış birey sendromuna (Baysan Arabacı, 2014), madde kullanımına (Karakurt, Smith ve Whiting, 2014; Delara, 2016; Uyar, Yıldırım Öztürk ve Şahin, 2018) ve mutsuzluk, üzgün olmak, suçluluk gibi psikolojik sağlık sorunlarına (Del Río Ferres, Megías ve Expósito, 2013; Baysan Arabac1, 2014; Karakurt, Smith ve Whiting, 2014; Hawcroft ve diğ. 2019), 
sosyal destekte azalmaya (Del Río Ferres, Megías ve Expósito, 2013) yol açtığ1 belirlenmiştir. Birleşmiş Milletler'e (2006) göre, engelli kadınlar engelli olmayan kadınlara göre, yaşamlarının bir noktasında daha fazla fiziksel istismar mağduru olmuştur. DSÖ 2013 analizi; fiziksel ya da cinsel istismara uğramış kadınların cinsel yolla bulaşan bir enfeksiyon geçirme ihtimalinin 1.5 kat daha fazla olduğunu, iki kat fazla kürtaj yapma durumu olduğunu, oranında düşük ağırlıklı doğum \% 16 ve premetüre doğum ihtimalinin \% 41 daha yüksek olduğunu, depresyon ve alkollü içki içme ihtimalinin neredeyse iki kat arttığını göstermiştir (WHO, 2017).

Sağlik profesyonelleri tarafından mağdurlara ve uygulayanlara yapılan girişimler, şiddetin oluşmasında ve etkilerinin azaltılmasında oldukça önem taşımaktadır (Akyurt, Sarı ve Şahin, 2008; Gharaibeh, Abu-Baker ve Aji, 2012; Bozkurt ve diğ. 2013; Kaplan ve diğ. 2014; Tambağ ve Turan, 2015; Sabancıŏulları ve diğ. 2016). Sağlık çalışanlarından, şiddet içeren durumlar yaşayanlara yeterli bakım ve destek sağlamada, önyargılardan ve damgalardan arınmış empatik bir tutum sergilemesi beklenmektedir. Temel amacı birey, aile ve toplum sağlığının geliştirilmesi olan hemşirelerin ve ebelerin, şiddet farkındalığ 1 oluşturma, şiddeti önleme, riskli grupların belirlenmesi, erken tanılama, güvenlik planlarının geliştirilmesinde, yardım ve desteğe erişimin kolaylaştırılmasında, şiddetten ve yol açtığı risklerden korunma ve müdahaledeki yeri ve rolleri inkâr edilemez (Baysan Arabac1, 2014; Dağlar, Bilgiç ve Demirel, 2017; Doran ve Hutchinson, 2017). Özellikle bu bireylerle karşılaşma olasılıkları yüksek psikiyatri, halk sağlı̆̆ı, kadın-doğum ve acil kliniklerinde çalışanlar ve ev ziyaretleri yapanlar çok özel konuma sahiptir (Baysan Arabacı, 2014; WHO, 2017). Ancak çalışma sonuçlarına göre sağlık çalışanlarının şiddeti sağlık sorunu olarak değerlendirme ve yönetme düzeylerinin düşük olduğunu (Gharaibeh, AbuBaker ve Aji, 2012; Kaplan ve diğ. 2014; Sabancioğulları ve diğ. 2016; Tambağ ve Turan, 2015), sağlık personelinin şiddeti ele almak ve önlemekten ziyade şiddetin yol açtığı fiziksel yaralanmalara bakma eğiliminde olduğunu göstermektedir (Natan ve diğ. 2016). Şiddet olayları günümüzde giderek artmakta olduğundan hemşirelik ve ebelik öğrencilerinin uygulama ortamlarında daha sık karşılaşabilecekleri bir sorun olacaktır. Ayrıca hemşirelik ve ebelik öğrencileri gelecekteki sağlık 
hizmeti sağlayıcılarıdır ve şiddeti önlemek, tanımlamak ve şiddetin etkilerini daha iyi anlamak ve yönetmek için gereken temel bilgi, eğitim ve pratik becerilerle donatılmaları gerekir (Gharaibeh, Abu-Baker ve Aji, 2012). Bununla birlikte, literatürde kadına yönelik şiddet konusunda öğrenciler için eğitim ve öğretim eksikliğini gösterilmiştir (Paulin Baraldi ve diğ. 2013; Tambağ ve Turan, 2015; Dağlar, Bilgiç ve Demirel, 2017). Ülkemizde şiddet gören kadınlarla karşılaşma olasılığı yüksek bir grup olan hemşire ve ebe öğrencilerle yapılan çalışmaların sonucunda öğrencilerin şiddet belirtilerini tanıma ve belirleme düzeyleri yetersiz bulunmuştur (Tambağ ve Turan, 2015; Dağlar, Bilgiç ve Demirel, 2017).

Şiddeti ele alma ve önlemedeki kilit rolü yerine getirmek için şiddete yönelik bireyin duygu, düşünce, algılamaları ve tutumlarının belirlenmesi son derece önemlidir. Bu çalışma, hemşirelik ve ebelik bölümü öğrencilerinin ailede kadına yönelik şiddet tutumlarının ve etkileyen faktörlerin değerlendirilmesi amacıyla kesitsel olarak yapılmıştır. Çalışma, öğrencilerin kadına yönelik şiddete ilişkin bakış açılarını ortaya koyması, öğrencilerin mesleki yaşamlarında kadına yönelik şiddet konusunda sorumluluk almaları için farkındalık oluşturması, öğrencilerin gelecekte kendilerinden beklenen kadına yönelik şiddete ilişkin tanılama, eğitim ve savunuculuk rollerine hazırlanmaları ve mezuniyet öncesi eğitim içeriklerinin düzenlenmesinde veri oluşturması açısından önemlidir.

\section{Yöntem}

\section{Araştırma Tipi ve Katılımcılar}

Kesitsel tipte gerçekleştirilen bu çalışmanın evrenini Kafkas Üniversitesi Sağlık Bilimleri Fakültesi'nde 2016-2017 akademik yılında eğitim gören 706 hemşirelik ve 153 ebelik öğrencisi oluşturmuştur. Sağlık Bilimleri Fakültesindeki tüm öğrenciler 4 yıl eğitim almakta olup, çeşitli derslerinde (Kadın Sağlığı ve Hastalıkları, Şiddet ve Yönetimi, Cinsel Sağlık, Aile İçi Şiddet ve Kadın) cinsiyet ayrımcllığı, şiddet ve farkındalığı arttıran çeşitli dersler almaktadır. Araştırmada örneklem seçimi yapılmamış, tüm öğrencilere ulaşılması hedeflenmiş, ancak 522 öğrenciden geçerli sonuç elde edilmiştir (\% 60.8). 


\section{Araştırma Soruları}

Araştırma kapsamına alınan bireylerin;

- Tanıtıcı ve şiddetle ilgili özellikleri nelerdir?

- Kadına yönelik şiddete ilişkin tutumları nasıldır?

- Kadına yönelik şiddete ilişkin tutumlarını etkileyen faktörler nelerdir?

\section{Veri Toplama Araçlan}

Çalışma verilerinin toplanmasında araştırmacıların litetür taraması (Gharaibeh, Abu-Baker ve Aji, 2012; Kanbay ve diğ. 2012; Ramsay ve diğ. 2012; Bozkurt ve diğ. 2013, Paulin Baraldi ve diğ. 2013; Sprague ve diğ. 2013; Kaplan ve diğ. 2014; Çelik ve diğ. 2015; Sabancığulları ve diğ. 2016; Er Güneri, 2016; Atasoy, 2017) sonucunda oluşturduğu bir anket formu ve Gömbül tarafından (2000) geliştirilen Kadına Uygulanan Şiddete İlişkin Tutum Ölçeği (ŞITÖ) kullanılmıştır. Anket formu öğrencilerin yaş, cinsiyet, sınıf, aile tipi, anne ve babanın eğitim durumu, ailenin gelir düzeyi, yaşanılan yer gibi demografik özellikleri; şiddete maruziyet ve şiddetle ilgili eğitim durumları gibi bilgileri içeren 23 soruluk bir formdur. Kadına ŞİTÖ; kocanın karısına uyguladığı şiddete ilişkin 19 tutum ifadesinden oluşmaktadır. Bu bölümde yer alan ifadeler kadına yönelik fiziksel, duygusal, psikolojik, cinsel, ekonomik şiddeti ve şiddete ilişkin mitleri içermektedir. Ekonomik şiddete ilişkin 7 soru $(9,14,15,16$, 17, 18, 19. ifadeler), duygusal, psikolojik, cinsel şiddete ilişkin 6 soru (7, $8,10,11,12$, 13. ifadeler), meşrulaştırıcı mitlere ilişkin 3 soru $(1,2,3$. ifadeler), neden açıklayıcı mitlere ilişkin 3 soru (4, 5, 6. ifadeler) bulunmaktadır. Likert tipi ölçekte; kesinlikle katılmıyorum "1", katılmıyorum "2", kararsizım "3", katılıyorum "4" ve tamamen katıllyorum "5" şeklinde puanlanmıştır. 19 sorunun 6'sı negatif yüklü maddelere karşlılk gelmekte$\operatorname{dir}(7,8,10,11,12,13$. ifadeler). Ölçekte alınabilecek ortalama tutum puanı 19 ile 95 arasında değişmektedir. Ölçek tutum puanı ortalaması $X=57$ ( $\min =19$, maks= 95)' dir. Alt ölçek tutum puan ortalamaları sırasıyla; ekonomik şiddet $X=21$ ( $\min =7$, maks= 35), duygusal, psikolojik, cinsel şiddet $X^{\prime}=18(\min =6$, maks=30), meşrulaştırıcı ve neden açıklayıcı mitler 
için ise $X=9(\min =3, \text { maks }=15)^{\prime}$ dur. Katılımcıların gruplardan aldıkları puanların yüksek olması şiddete ilişkin tutumlarda geleneksellikte artmayı, düşük olması ise azalmayı yansıtmaktadır (Gömbül 2000).

\section{Verilerin Analizi}

Çalışmada elde edilen veriler SPSS 20.0 programında analiz edilmiştir. Verilerin dağılımı için Kolmogorov-Smirnov testi ile normallik analizi yapılmıştır. Tanımlayıcı istatistiksel metodların (ortalama, sayı, yüzdelik) yanısıra, iki grup ortalamalarını karşılaştırmada Mann Whitney $\mathrm{U}$, ikiden fazla grubun ortalamaları arasındaki farkın belirlenmesinde Kruskal Wallis ve ordinal değişkenler arasındaki ilişkiyi belirlemede Spearman's rho Korelasyon analizi kullanılmıştır. $\mathrm{p}<0.05$ değeri istatistiksel olarak anlamlı kabul edilmiştir.

\section{Araştırmanın Etik Yönü}

Çalışma için Kafkas Üniversitesi Tıp Fakültesi Etik Kurul başkanlığından (01.03.2017 tarihli ve 8057635.1-050-99/46 say1l1) ve Kafkas Üniversitesi Sağlık Bilimleri Fakültesi Dekanlığg'ndan (27.03.2017 tarih ve 81829502/900/77 sayıl1) kurum izni alınmıştır. Araştırmada kullanılan ölçüm araçlarını geliştiren kişilerden e-mail aracılı̆̆ıyla izin alınmıştır. Araştırmaya katılacak öğrencilerden ise araştırmanın amacı anlatıldıktan sonra sözel onam/onayları alınmış ve gönüllülük esasına dikkat edilmiştir.

\section{Bulgular}

Bu bölümde araştırmaya katılan öğrencilerin tanıtıcı özellikleri, şiddete uğrama özellikleri, ŞiTÖ puan ortalamaları, ŞíTÖ'yü etkileyen faktörler incelenmiştir.

Araştırmaya katılan öğrencilerin tanıtıcı özelliklerine bakıldığında; yaş ortalamasının $21.08 \pm 1.98$ (min:17, max:32) olduğu, öğrencilerin \% 63.4'ünün kı, \% 32.4'ünün birinci sinıf, \% 80.1'inin hemşirelik bölümünde okuduğu, \% 98.1'inin bekâr, \% 37.4'ünün yaşamının çoğunun şehirde geçirdiği, \% 74.9'unun çekirdek ailesinin olduğu, \% 
46.4'ünün yurtta yaşadığ ${ }_{1}, \%$ 64.2'sinin gelir durumunun orta düzeyde olduğu, \% 35.4'ünün annesinin okur-yazar olmadığı, \% 92.1'inin annesinin çalışmadığı, \% 37.2'sinin babasının ilkokul mezunu olduğu ve \% 69.5'inin babasının çalıştı̆̆ belirlenmiştir. Ayrıca demografik özellikler ayrıntılı olarak Tablo 2'de görülmektedir.

Araştırmaya katılan öğrencilerin şiddete uğrama özelliklerine bakıldığında; öğrencilerin \% 39.7'sinin şiddet gördüğü (\% 55.5'inin duygusal, \% 37.7'sinin fiziksel, \% 0.3'ünün cinsel ve \% 6.5'inin ekonomik) şiddeti ilk sırada baba daha sonra annenin uyguladığı, \% 39.8'inin şiddet karşısında sustuğu, \% 29.9'unun özür dilenme sonucu barıştığı, \% 9.9'unun şiddet uygulayanla bağını kopardığı, \% 7'sinin evden ayrıldığı, $\% 0.7^{\prime}$ sinin karakola gittiği ve \% 12.8 'inin diğer yolları tercih ettiği ve \% 84.5'inin devam eden bir şiddet durumunun olmadığı belirlenmiştir. Ayrıca şiddete uğrama özellikleri ayrıntılı olarak Tablo 3 'te de görülmektedir.

Öğrencilerin Kadına Uygulanan Şiddete İlişkin Tutum Ölçeği (ŞiTÖ) alt boyut ve toplam puanlarının karşılaştırılmasına bakıldığında (Tablo 1); puanların ortalamanın altında olduğu, şiddete ilişkin tutumlarında geleneksellikten ziyade çağdaş tutumların olduğu görülmektedir.

Tablo 1. Öğrencilerin Kadına Uygulanan ŞİTÖ Puan Ortalamaları (n=522)

\begin{tabular}{lcll}
\hline & $\begin{array}{l}\text { Alınabilecek } \\
\text { Minimum-Maximum }\end{array}$ & $\begin{array}{l}\text { Alınan } \\
\text { Minimum-Maximum }\end{array}$ & X \pm S.S \\
\hline Ekonomik Şiddet & $7-35$ & $7-35$ & $15.04 \pm 6.17$ \\
\hline $\begin{array}{l}\text { Duygusal, Psikolojik, } \\
\text { Cinsel Şiddet }\end{array}$ & $6-30$ & $6-30$ & $12.90 \pm 4.88$ \\
\hline Meşrulaştırıcı Mitler & $3-15$ & $3-15$ & $5.88 \pm 2.65$ \\
\hline Neden Açılklayıcı Mitler & $3-15$ & $3-15$ & $7.03 \pm 2.53$ \\
\hline Genel Şiddet & $19-95$ & $19-87$ & $40.86 \pm 12.25$ \\
\hline
\end{tabular}

Öğrencilerin ŞiTÖ puan ortalamalarını etkileyen tanıtıcı özelliklerine bakıldığında (Tablo 2); erkek öğrencilerin kız öğrencilere (U=13.603; $\mathrm{p}=0.000)$, hemşirelik öğrencilerinin ebelik öğrencilerine (U=5.347; $=0.000)$, köyde yaşayanların şehirde $(\mathrm{U}=-2.324 ; \mathrm{p}=0.020)$ ve büyükşehirde yaşayanlara ( $\mathrm{U}=-3.408 ; \mathrm{p}=0.001)$, kasaba/ilçede yaşayanların büyük şehirde yaşayanlara $(U=-2.314 ; p=0.021)$, geniş $(U=-$ 2.368; $\mathrm{p}=0.018$ ) ve parçalanmış $(\mathrm{U}=-2.511 ; \mathrm{p}=0.012)$ ailesi olanların çekirdek 
ailesi olanlara, arkadaşıyla yaşayanların ailesiyle $(\mathrm{U}=-3.153 ; \mathrm{p}=0.002)$ ve yurtta yaşayanlara $(\mathrm{U}=-3.781 ; \mathrm{p}=0.000)$, gelir durumu kötü olanların iyi $(\mathrm{U}=-2.946 ; \mathrm{p}=0.003)$ ve orta olanlara $(\mathrm{U}=-2.080 ; \mathrm{p}=0.038)$, annesi okuryazar olmayanların ilkokul $(\mathrm{U}=-3.713 ; \mathrm{p}=0.000)$ ve lise mezunu olanlara ( $\mathrm{U}=-$ 2.032; $\mathrm{p}=0.042)$, babası çalışmayanların çalışanlara $(\mathrm{U}=-3.497 ; \mathrm{p}=0.000)$ göre istatistiksel olarak anlamlı derecede daha yüksek olduğu görülmüştür. Yaş ile şiddet puanı arasında yüksek düzeyde pozitif ilişki $(r=0.088 ; p=0.046)$ olduğu görülmektedir.

Tablo 2. Öğrencilerin Tanıtıcı Özelliklerine Göre ŞİTÖ Puan Ortalamaları (n=522)

\begin{tabular}{|c|c|c|c|c|}
\hline \multirow[b]{2}{*}{ Özelikler } & \multirow[b]{2}{*}{$\mathbf{n}$} & \multirow[b]{2}{*}{$\%$} & \multicolumn{2}{|c|}{ Puan Ortalaması } \\
\hline & & & Mean Rank & $\mathrm{U} ; \chi^{2} / \mathrm{p}$ \\
\hline \multicolumn{5}{|l|}{ Cinsiyet } \\
\hline $\mathrm{K}_{1 z}$ & 331 & 63.4 & 193.31 & $\mathrm{U}=-13.603$ \\
\hline Erkek & 191 & 36.6 & 379.68 & $\mathrm{p}=\mathbf{0 . 0 0 0}$ \\
\hline \multicolumn{5}{|l|}{ Sinif } \\
\hline 1.sinif & 169 & 32.4 & 272.30 & \\
\hline 2.sinif & 127 & 24.3 & 277.38 & $\chi^{2}=5.167$ \\
\hline 3.sinif & 94 & 18.0 & 242.87 & $\mathrm{p}=0.160$ \\
\hline 4.sinif & 132 & 25.3 & 245.67 & \\
\hline \multicolumn{5}{|l|}{ Bölüm } \\
\hline Hemşirelik & 418 & 80.1 & 279.10 & $\mathrm{U}=-5.347$ \\
\hline Ebelik & 104 & 19.9 & 190.76 & $\mathrm{p}=0.000$ \\
\hline \multicolumn{5}{|l|}{ Medeni Durum } \\
\hline Bekâr & 512 & 98.1 & 260.48 & $\mathrm{U}=0.255$ \\
\hline Evli & 10 & 1.9 & 313.70 & $\mathrm{p}=0.614$ \\
\hline \multicolumn{5}{|l|}{ Yaşanilan Yer } \\
\hline Köy & 92 & 17.6 & 299.74 & \\
\hline Kasaba & 135 & 25.9 & 269.47 & \\
\hline Şehir & 195 & 37.4 & 255.11 & $\chi^{2}=13.054$ \\
\hline Büyük Şehir & 95 & 18.1 & 223.82 & $\mathrm{p}=0.011$ \\
\hline Yurt Diş1 & 5 & 1.0 & 307.90 & \\
\hline \multicolumn{5}{|l|}{ Aile Yapısı } \\
\hline Çekirdek Aile & 391 & 74.9 & 249.89 & \\
\hline Geniş Aile & 108 & 20.7 & 288.46 & $\chi^{2}=10.843$ \\
\hline Parçalanmış Aile & 23 & 4.4 & 332.30 & $\mathrm{p}=0.004$ \\
\hline \multicolumn{5}{|c|}{ Birlikte Yaşanılan Kişi/Yer } \\
\hline Aile & 165 & 31.6 & 245.38 & $\chi^{2}=15.212$ \\
\hline Arkadaş & 115 & 22.0 & 303.07 & $\mathrm{p}=0.000$ \\
\hline Yurt & 242 & 46.4 & 240.15 & \\
\hline \multicolumn{5}{|l|}{ Gelir Durumu } \\
\hline İyi & 60 & 11.5 & 219.59 & $\chi^{2}=9.507$ \\
\hline
\end{tabular}




\begin{tabular}{|c|c|c|c|c|}
\hline Orta & 335 & 64.2 & 258.02 & $\mathrm{p}=0.009$ \\
\hline Kötü & 127 & 24.3 & 290.48 & \\
\hline \multicolumn{5}{|c|}{ Anne Eğitim Durumu } \\
\hline Okuryazar Değil & 185 & 35.4 & 291.80 & \multirow{6}{*}{$\begin{array}{l}\chi^{2}=14.174 \\
\mathbf{p}=\mathbf{0 . 0 1 5}\end{array}$} \\
\hline Okuryazar & 57 & 10.9 & 267.40 & \\
\hline İlkokul Mezunu & 176 & 33.7 & 234.64 & \\
\hline Ortaokul Mezunu & 44 & 8.4 & 260.53 & \\
\hline Lise Mezunu & 46 & 8.8 & 240.43 & \\
\hline Yükseköğretim & 14 & 2.7 & 247.00 & \\
\hline \multicolumn{5}{|c|}{ Anne Çalışma Durumu } \\
\hline Evet & 37 & 7.1 & 245.76 & \multirow{2}{*}{$\begin{array}{l}\mathrm{U}=-0.659 \\
\mathrm{p}=0.510\end{array}$} \\
\hline Hayır & 485 & 92.9 & 262.70 & \\
\hline \multicolumn{5}{|c|}{ Baba Eğitim Durumu } \\
\hline Okuryazar Değil & 34 & 6.5 & 291.71 & \multirow{6}{*}{$\begin{array}{l}\chi^{2}=3.646 \\
p=0.003\end{array}$} \\
\hline Okuryazar & 48 & 9.2 & 306.00 & \\
\hline İlkokul Mezunu & 194 & 37.2 & 281.10 & \\
\hline Ortaokul Mezunu & 79 & 15.1 & 247.27 & \\
\hline Lise Mezunu & 109 & 20.9 & 225.84 & \\
\hline Yükseköğretim & 58 & 11.1 & 227.78 & \\
\hline \multicolumn{5}{|c|}{ Baba Çalışma Durumu } \\
\hline Evet & 363 & 69.5 & 246.23 & \multirow{2}{*}{$\begin{array}{l}U=-3.497 \\
p=0.000\end{array}$} \\
\hline Hayır & 159 & 30.5 & 296.37 & \\
\hline
\end{tabular}

Öğrencilerin ŞíTÖ puan ortalamalarını etkileyen şiddetle ilgili özelliklerine bakıldığında (Tablo 3); şiddete ilişkin eğitim almayanlardan almak istemeyenlerin eğitim almak isteyenlere $(U=-5.679 ; p=0.000)$, kadına yönelik şiddetle ilgili talimat ve prosedürleri istemede herhangi bir fikri olmayan ya da istemeyenlerin isteyenlere $\left(\chi^{2}=26.050 ; p=0.000\right)$, kadına yönelik şiddet olgu/şüphesini bildirmede istemeyenlerin isteyen ve şiddetin özelliğine göre isteyenlere $\left(\chi^{2}=58.377 ; p=0.000\right)$ göre istatistiksel olarak anlamlı derecede daha yüksek olduğu görülmektedir. 
Tablo 3. Öğrencilerin Şiddetle İlgili Özelliklerine Göre ŞíTÖ Puan Ortalamalan $(n=522)$

\begin{tabular}{|c|c|c|c|c|}
\hline \multirow[b]{2}{*}{ Özellikler } & \multirow[b]{2}{*}{$\mathbf{n}$} & \multirow[b]{2}{*}{$\%$} & \multicolumn{2}{|c|}{ ŞíTÖ } \\
\hline & & & Mean Rank; & $\mathrm{U} ; \chi^{2} / \mathrm{p}$ \\
\hline \multicolumn{5}{|l|}{ Şiddet Görme } \\
\hline Evet & 207 & 39.7 & 270.10 & $\mathrm{U}=-1.057$ \\
\hline Hayır & 315 & 60.3 & 255.85 & $\mathrm{p}=0.291$ \\
\hline \multicolumn{5}{|l|}{ Halen Şiddet Varlığ 1} \\
\hline Evet & 81 & 15.5 & 247.71 & $\mathrm{U}=-0.896$ \\
\hline Hayır & 441 & 84.5 & 264.03 & $\mathrm{p}=0.370$ \\
\hline \multicolumn{5}{|l|}{ Şiddete Tanık Olma } \\
\hline Evet & 229 & 43.9 & 259.37 & $U=-0.286$ \\
\hline Hayır & 293 & 56.1 & 263.17 & $\mathrm{p}=0.775$ \\
\hline \multicolumn{5}{|l|}{ Şiddete İlişkin Eğitim Alma } \\
\hline Evet & 225 & 43.1 & 268.52 & $\mathrm{U}=-0.925$ \\
\hline Hayır & 297 & 56.9 & 256.19 & $\mathrm{p}=0.355$ \\
\hline \multicolumn{5}{|l|}{ Alınmadıysa Alma İsteği } \\
\hline Evet & 322 & 85.4 & 175.83 & $U=-5.679$ \\
\hline Hayır & 55 & 14.6 & 266.09 & $p=0.000$ \\
\hline \multicolumn{5}{|c|}{ Kadına Yönelik Şiddetle İlgili Talimat/Prosedürü İsteme } \\
\hline Evet & 461 & 88.3 & $39.55 \pm 11.41$ & \\
\hline Hayır & 20 & 3.8 & $47.40 \pm 17.87$ & $\chi^{2}=26.050$ \\
\hline Fikrim Yok & 41 & 7.9 & $52.43 \pm 11.25$ & $\mathrm{p}=\mathbf{0 . 0 0 0}$ \\
\hline \multicolumn{5}{|c|}{ Kadına Yönelik Şiddet Olgu/ Şüphesini Bildirme } \\
\hline Evet & 409 & 78.4 & 235.74 & \\
\hline Hayır & 25 & 4.7 & 402.60 & $\chi^{2}=58.377$ \\
\hline Şiddetin Özelliğine Göre & 88 & 16.9 & 341.13 & $\mathrm{p}=\mathbf{0 . 0 0 0}$ \\
\hline
\end{tabular}

\section{Tartışma}

Sadece kadın olmanın şiddete uğramak için yeterli olduğu, kadının olduğu her yerde evrensel bir sorun olmaya devam eden insan haklarının ihlali olan kadın şiddetinin heteroseksist-ataerkil ekseni barındıran Türkiye'de disiplin yöntemi olarak algilanması; şiddetin sürekliliği, gizlenmesi veya yok sayılmasına yol açmaktadır (Taşdemir Afşar, 2015). Hemşirelik ve ebelik öğrencilerinin, yani gelecekteki hemşire ve ebelerin, aile içi şiddete yönelik aktif rol alabilmeleri için, şiddete maruz kalan kadınlara yardımcı olacak bilgi ve becerilere sahip olmaları gerekir. Ayrıca, öğrencilerin aile içi şiddete karşı tutumlarının farkında olmaları ve farkındalıklarını arttırmaları ve duyarlı olmalarını sağlamak önemlidir. Bu nedenle, öğrencilerin aile içi şiddete yönelik 
tutumlarını belirlemek ve bunun farkındalığını artırmak gerekmektedir. Bu çalışma, hemşirelik ve ebelik öğrencilerinin aile içinde kadına yönelik şiddette ilişkin tutumlarını ve etkileyen faktörleri belirlemek amacıyla yapilmıştır.

Bu araştırmada öğrencilerin \% 39.7'sinin şiddet gördüğü (\% 55.5'inin duygusal, \% 37.7'sinin fiziksel, \% 0.3'ünün cinsel ve \% 6.5'inin ekonomik) belirlenmiştir. Türkiye'de çeşitli araştırma sonuçlarına göre hemşire ve ebe öğrencilerin \% 15.5-61.1 arasında şiddete uğradığ1 görülmüştür (Kanbay ve diğ. 2012; Bozkurt ve diğ. 2013; Er Güneri, 2016; Dağlar, Bilgiç ve Demirel, 2017; Çıtak Tunç, Çıtak Bilgin ve Kılınç, 2018). Araştırma sonuçlarının farklı oranlarda görülmesi yapılan bölgeler arasındaki kültürel değer farklılığı, cinsiyet farklılığı ve zamana bağlı olabilir. Karabulutlu'nun hemşirelik öğrencileriyle yaptığ ${ }_{1}$ çalışmada (2015); \% 24.5 oranda en fazla duygusal şiddetin yaşandığını ifade etmesi bu çalışma ile benzerdir.

$\mathrm{Bu}$ araştırmada öğrencilerin \% 43.9'unun aile içinde şiddete tanık olduğu görülmektedir (Tablo 3). Ebelik ve hemşirelik öğrencileri ile yapılan çalışmalarda aile içerisinde şiddete tanık olma oranlarına bakıldığında; Kanbay ve diğerlerinde (2012) \% 43.3, Bozkurt ve diğerlerinde (2013) \% 36.2, Karabulutlu'nun (2015) çalışmasında \% 29, Dağlar, Bilgiç ve Demirel'de \% 15.2, Çıtak Tunç, Çıtak Bilgin ve Kılınç'ta , (2018) \% 68 olarak görülmüştür. Sabancıoğulları ve arkadaşlarının (2016) çalışmasında da öğrencilerin yarısının kadına yönelik şiddete tanık olduğu ve beşte birinin çevresinde bu durumun olduğu görülmektedir. Öğrencilerin kadına yönelik şiddete tanık olma sıklıklarının yüksek olması, kadına yönelik şiddet farkındalıklarının arttırılmasının önemini ortaya koymaktadır.

$\mathrm{Bu}$ araştırmada öğrencilerin \% 43.1'inin şiddete ilişkin derslerinde eğitim aldığı, \% 85.4'ünün daha kapsamlı bir eğitim almak istediği belirlenmiştir (Tablo 3). Bozkurt ve diğerlerinin (2013) yaptıkları çalışma sonucunda; öğrencilerin \% 39.1'inin şiddete ilişkin derslerinde eğitim aldığı, \% 96.3'ünün daha kapsamlı bir eğitim almak istediği belirlenmiştir. Elmalı ve diğerlerinin (2011) çalışmaları sonucunda öğrencilerin \% 92.9'unun şiddete yönelik hiçbir eğitim almadığ aile içi şiddet vakalarını belirleyemediği ve tanımlayamadığı ve tüm öğrencilerin bu konuda eğitim almak istediği görülmüştür. Dağlar, Bilgiç 
ve Demirel'in çalışmalarında (2017) \% 57.2'sinin derslerinde şiddet konusunun işlendiği ve \% 34.6'sının şiddete uğrayan bir kadına yaklaşımda bulunabileceği belirlenmiştir. Atasoy'un ebelik öğrencileri ile çalışmasında (2017), öğrencilerin \%75.7'si tarafından, aile içi şiddetin önlenmesinde ebelerin rolü olacağını belirtmiştir. Yapılan araştırma sonuçları, öğrencilerin çoğunun, aile içi şiddeti belirleme ve başa çıkma konusunda hazırlıksız olduklarını, bilgi ve beceri eksikliklerinin olduğunu göstermektedir.

Öğrencilerin şiddete karşı geleneksel olmaktan uzak bir çağdaş tutuma sahip oldukları belirlenen bu araştırmada genel şiddet puan ortalamas1 $40.86 \pm 12.25$ olup, alt boyutlarda ekonomik şiddet $15.04 \pm 6.17$, duygusal, psikolojik, cinsel şiddet $12.90 \pm 4.88$, meşrulaştırıcı mitler 5.88 \pm 2.65 ve neden açıklayıcı mitler'in $7.03 \pm 2.53$ puan olduğu görülmektedir (Tablo 1). Görülen bu sonuçlar profesyonel bir sağlık meslek üyesi olmaya aday hemşirelik ve ebelik öğrencilerinin geleneksellikten uzak, kadını destekleyici modern ve çağdaş tutum içinde bulunmalarından dolayı sevindirici bir bulgudur. Doğu kültüründe kadına yönelik şiddet, toplum tarafından kabul edilmekte olup, erkekler tarafından kadınlara karşı şiddet uygulanması normal bir davranış olarak görülmektedir (Ortabag ve diğ. 2014). Türkiye'de araştırma sonuçları karşılaştırıldığında Er Güneri'nin (2016) İzmir'de, Sabancioğulları ve diğerlerinin (2016) Sivas'ta, Dağlar, Bilgiç ve Demirel'in, (2017) Sivas'ta, Mermer ve Öztürk Dönmez' in (2018) İzmir'de yaptıkları çalışmalar sonucunda bu araştırmadaki ortalama puanlardan daha düşük puan aldıkları ve kadına şiddete yönelik tutumlarının daha çağdaş yaklaşım içinde olduğu görülmektedir. Sabancığulları ve diğerlerinin (2016) şiddete ilişkin tutum puan ortalamaları $38.99 \pm 10.77$ olarak bulunmuştur. Bu araştırmalarda puan ortalamalarının bu araştırmadan daha düşük olmasının nedeni çalışmalarının şehrimizin bulunduğu bölgeye göre Türkiye'nin batısında yapılmalarından ve çalışmaya katılanların büyük çoğunluklarının kız öğrencilerden oluşmasına bağlı olabilir. Sabancıoğulları ve diğerlerinin (2016) çalışmalarında Doğu ve Güney Doğu Anadolu bölgesinde yaşayan öğrencilerin daha geleneksel tutumlarının olduğu görülmesi de bu sonucu desteklemektedir. Connor ve diğeri (2013), hemşirelik öğrencilerinin şiddete karşı istenen bir tutuma sahip olduklarını belirtmiştir. Hemşirelik öğrencileri ile yapılan bu çalışmaların sonuçları olumlu iken, 
öğrencilerin kadına karşı şiddet tutumlarında geleneksel bir bakış açısı olduğunu belirleyen çalışmalar vardır (Kanbay ve diğ. 2012; Kaplan ve diğg. 2014). Karabulutlu'nun çalışmasında (2015); öğrencilerin yarısına yakınının toplumsal cinsiyet eşitliğine yönelik tutumlarının olumsuz olduğu belirlenmiştir. Gharaibeh, Abu-Baker ve Aji'nin Suriyeli tıp ve hemşirelik öğrencileri arasında kadın istismarı ilişkin algı ve tutumlarını araştırma amaçlı 621 öğrenci ile yaptıkları çalışma sonucunda (2012); öğrencilerin \% 17.7'sinin şiddete yönelik olumsuz, sadece\% 18.4'ünün şiddete yönelik olumlu tutumlarının olduğu, \% 63.9'unun bu konuda tarafsız olduğu görülmüştür.

$\mathrm{Bu}$ çalışmada erkeklerin kız öğrencilere göre daha geleneksel tutum içinde oldukları görülmüştür. Çalışmanın bu bulgusu literatür sonuçlarıyla paralellik göstermektedir (Gharaibeh, Abu-Baker ve Aji, 2012; Kaplan ve diğ. 2014; Er Güneri, 2016; Sabancioğulları ve diğ. 2016; Dağlar, Bilgiç ve Demirel, 2017; Doran ve Hutchinson, 2017; Mermer ve Öztürk Dönmez, 2018). Mermer ve Öztürk Dönmez'in (2018) hemşirelik öğrencileri ile çalışmalarında kız öğrencilerin erkeklerden 4 kat daha çağdaş tutumlara sahip oldukları belirlenmiştir. Birçok çalışmada, erkeklerin kadınlardan daha fazla şiddete maruz kaldıkları bulunmuştur (Agrawal ve Banerjee, 2010; Gharaibeh, Abu-Baker ve Aji, 2012; Sabancıoğulları ve diğ. 2016). Bu durum, erkeklerin yaşadığını benimsemesinin ve daha geleneksel bir role sahip olmasının tetikleyicisi olabilir. Ayrıca erkeklerin kadınlara yönelik puanlarının daha yüksek olması; kızların ve erkeklerin yetiştirilme biçimlerinin farklı olması, toplumsal cinsiyet rollerine bağlı kaynaklı olabilir. Pekçok toplumda kadınlara yumuşaklık, ilgi, sevgi gösterme, itaat, besleyip yetiştirme gibi özellikler öğretilirken; erkeklere güçlü, saldırgan, yarışmacı ve rekabet içinde olma özellikleri aşılanır ve ev halkının reisi ve mülkiyetin yöneticisi ve sahibi olmaları istenir (Akkuş ve Yıldırım, 2018).

Bu çalışmada hemşirelik öğrencilerinin ebelikte okuyan öğrencilere göre şiddete yönelik tutumlarının daha geleneksel oldukları görülmüştür. Dağlar, Bilgiç ve Demirel'in (2017) yaptıkları çalışmada da benzer sonuç görülmüştür. Çalışmanın bu sonuçları ebelik öğrencilerinin tümünün kız olmasından kaynaklanabilir.

$\mathrm{Bu}$ çalışmada sınıfların şiddete yönelik tutumda istatistiksel olarak anlamlı fark oluşturmadığı görülmüştür. Bu sonuç genellikle son sınıf 
öğrencilerinin geleneksellikten uzak, daha modern ve çağdaş bir tutumlarının olduğunu gösteren çalışma sonuçlarıyla uyumsuzdur (Er Güneri, 2016; Dağlar, Bilgiç ve Demirel, 2017; Mermer ve Öztürk Dönmez 2018). Konuyla ilgili yapılan çalışmalardan, verilen mesleki eğitimin şiddete yönelik çağdaş tutumu arttırmada etkili olduğu tespit edilmiştir (Er Güneri, 2016; Sabancıoğulları ve diğ. 2016). Gharaibeh, Abu-Baker ve Aji'nin (2012) çalışmasında yaş arttıkça şiddete yönelik tutum geleneksellikten uzaklaşmaktadır. Ayrıca sınıf yükseldikçe yaşın artması da bu duruma neden olabilir.

$\mathrm{Bu}$ çalışmada geleneksel tutumun metropolden köye doğru yükseldiği tespit edilmiştir. Bu sonuç literatür bulgularıyla paralellik göstermektedir (Gömbül 2000; Gharaibeh, Abu-Baker ve Aji, 2012; Er Güneri, 2016; Sabancığulları ve diğ. 2016; Dağlar, Bilgiç ve Demirel, 2017; Mermer ve Öztürk Dönmez, 2018). Bu sonuç köyde gelenek ve göreneklerin daha baskın olmasına, şiddete ilişkin inanışların daha kolay şekilde aktarılmasına, şehirde bu konuda eğitim imkanlarının daha fazla olmasına ve şiddet tutumunun daha hoş karşılanmamasına bağlı olabilir.

Bu çalışmada geniş ve parçalanmış ailesi olanların şiddete yönelik tutumlarının daha geleneksel olduğu görülmüştür. Çalışmanın bu sonucu Dağlar, Bilgiç ve Demirel'in (2017) çalışmaları ile uyumluluk gösterirken, Sabancıoğulları ve diğerlerinin (2016) çalışmasında aile tipinin şiddete yönelik tutumu etkilemediği görülmüştür.

Bu çalışmada arkadaşıyla yaşayanların ailesiyle ve yurtta yaşayanlara göre şiddete yönelik tutumlarının daha geleneksel olduğu görülmüştür. Mermer ve Öztürk Dönmez'in hemşirelik öğrencileri (2018) ile çalışmalarında aileleriyle birlikte yaşayan hemşirelik öğrencileri şiddete karşı yurtlarda ve arkadaşlarıyla yaşayanlardan daha çağdaş bir tutum sergilemiştir. Bu bulgular, bireylerin yaşadığı toplumun ve aile yapısının tutumlarını etkilediğini göstermektedir. Bu sonuç aile ve yurtta belirli davranış ve sosyalizasyon kurallarının olmasından, ilişki ve iletişimde şiddetin kısıtlılığından kaynaklanabilir.

$\mathrm{Bu}$ çalışmada gelir durumu kötü olanların iyi olanlara göre şiddete yönelik tutumlarının daha geleneksel olduğu görülmüştür. Çalışmanın bu sonucu Sabancığulları ve diğerlerinin (2016) çalışmaları ile uyumluluk gösterirken, Mermer ve Öztürk Dönmez'in (2018) çalışmalarında aile tipinin şiddete yönelik tutumu etkilemediği görülmüştür. 
Bu çalışmada annesi okuryazar olmayanların ilkokul ve lise mezunu olanlara göre şiddete yönelik tutumlarının daha geleneksel olduğu; baba eğitiminin ise etkili olmadığı belirlenmiştir. Eğitim bireylerin tutum ve yaklaşımlarını etkilemektedir ve tutum değişikliğine ancak eğitim yoluyla ulaşılabilir. Bu konuda yapılan çalışmalarda değiş̧ik bulgular görülmüştür. Ebeveyn eğitiminin çocuğun şiddet tutumunu etkilemediğini belirten çalışma sonuçlarının yanı sıra (Kodan Çetinkaya, 2013; Mermer ve Öztürk Dönmez, 2018), ebeveyn eğitim düzeyi arttıkça öğrencilerin şiddete yönelik tutumlarının geleneksellikten çekildiğini gösteren çalışmalar da vardır (Gharaibeh, Abu-Baker ve Aji, 2012; Dağlar, Bilgiç ve Demirel, 2017).

$\mathrm{Bu}$ çalışmada hem şiddet görme öyküleri ve hem de şiddetin devam etme durumunun öğrencilerin şiddete yönelik tutumlarında istatistiksel olarak etkili olmadığı belirlenmiştir. Oysa ki, şiddet ile ilgili yapılan çalışmalarda, şiddete uğrama öyküsünün şiddet tutumları üzerinde olduğu belirtilmektedir (Kodan ve Çetinkaya, 2013; Sabancıŏulları ve diğ. 2016; Dağlar, Bilgiç ve Demirel, 2017). Bunun nedeni sosyal öğrenme modeline göre şiddetin öğrenilmesi ve gelecek nesillere taşınması düşüncesidir (Speizer, 2010; Gharaibeh, Abu-Baker ve Aji, 2012; Bozkurt ve diğ. 2013; Kaplan ve diğ. 2014). Bu sonuç öğrencilerin çoğunluğunu ataerkil tutum, cinsiyet ayrımcllığı ve şiddetin daha yoğun görüldüğü Doğu ve Güney Doğu Anadolu bölgesinde yaşayıp şiddeti daha fazla benimsemiş olmasından kaynaklı olabilir.

$\mathrm{Bu}$ çalışmada öğrencilerin çoğunluğunun (\% 85.4) şiddet konusunda almadığı eğitimi almak istediğini ifade etmesi sevindirici olup, kadın ve halk sağlığı açısından çok önemlidir. Şiddete yönelik eğitimin, şiddetin bir sağlık sorunu olarak ele alınması ve tanımlanabilmesinde önemli olduğu belirtilmektedir (Watts ve Mayhew, 2004). Şiddetin bir sağlık sorunu olarak fark edilmesi ve tanımlanmasında bilgisinin yeterliliği ve eğitim önemli olup, bilgi yetersizliği şiddeti saptamada engel bir durum olarak karşımıza çıkmaktadır (Gharaibeh, Abu-Baker ve Aji, 2012).

$\mathrm{Bu}$ çalışmada şiddete yönelik eğitim almak istemeyenlerin eğitim almak isteyenlere göre tutumlarında gelenekselliğin arttığı saptanmıştır. $\mathrm{Bu}$ sonuç litaratürle paralellik göstermektedir (Er Güneri, 2016; Sabancıoğulları ve diğ. 2016). Türkiye'de, toplumsal cinsiyet eşitliğii, şiddet, aile içi şiddet ve şiddeti önleyici programcılar hakkında sınırlı 
sayıda eğitim bulunmaktadır (Çıtak Tunç, Çıtak Bilgin ve Kılınç, 2018). Dersler sadece teorik anlamda verilmektedir, bununla ilgili klinik deneyim ya da simülasyon çalışmaları yapılmamaktadır. Tambağ ve Turan'ın (2015) hemşirelik öğrencilerinin şiddet belirtilerini tanımlamada yetersiz oldukları görülmüştür. Ramsay ve diğerlerinin (2012) Birleşik Krallık'ta yaptıkları bir çalışmada 272 doktor ve hemşirenin aile içi şiddet konusunda temel bir bilgisi olduğu, aile içi şiddet hakkında soru sormak için yeterince hazırlıklı olmadığı ve istismara uğramış kadınlarla ilgilenme konusunda olumlu bir tutum sergilemelerine rağmen değerlendirme ve müdahale konusunda daha fazla eğitim gerekli olduğu bildirilmiştir. 200'den fazla tıp ve cerrahi öğrencisiyle yapılan bir başka Kanada araştırmasında, öğrencilerde aile içi şiddet mağdurlarının özellikleri hakkındaki mitleri de içeren birçok önyargı bulunmuştur. Yine, bu çalışmadaki öğrencilerin çoğu, eğitim seviyelerinin yetersiz olduğunu ve aile içi şiddeti tanımlamanın uygulamalarıyla çok ilgili olduğuna inandığını belirtmiştir (Sprague ve diğ. 2013). Birleşik Krallık'ta 55 lisans hemşirelik ve ebelik öğrencisi ile yapılan kalitatif bir çalışmada da öğrencilerin çoğu, aile içi istismarı tanımlama ve başa çıkma konusunda hazırlıksız olduklarını bildirmişlerdir (Bradbury Jones ve Broadhurst, 2015). Natan ve diğerlerinin (2016), hemşirelik öğrencilerinin kadınları aile içi şiddete karşı taramaya hazır oluşlarını değerlendirme amaçlı yaptıkları çalışmada; hemşirelik öğrencilerinin, tedavi verirken kadınların aile içi şiddete karşı tarama niyetinin yüksek olduğunu; normatif inançlar, öznel normlar, davranışsal inançlar, algılanan kontrol ve bilgi, öğrencilerin aile içi şiddete karşı kadınları tarama niyetini etkilediğini ve klinik öğretim elemanının görüşünün aile içi şiddeti taramada öğrenciler için en önemli belirleyici olduğu görülmüştür. Hem lisansta hem de uygulamada hizmet içi ve sürekli müfredatının bir parçası olan eğitim, aile içi şiddet yaşayan kadınlara yönelik uygulamada daha destekleyici olmalıdır. Üniversitedeki lisans dersleri aile içi şiddet hakkındaki tutumlarda bir değişiklik başlatmak ve mezunlarını kapsamlı bir aile içi şiddet yönelik uygulama becerileri ile donatmak için ideal bir firsattır. Ancak, aile içi şiddete yönelik lisans eğitimi çoğu zaman eksiktir. Sağlık öğrencilerinin aile içi şiddete yönelik bilgi düzeyi arttıkça empatik ve destekleyici tutum ve yaklaşımının da artacağı düşünülmektedir. 
Bu çalışmadan genelleştirme ve nedensel çıkarımlar yapma imkânı sinırlıdır, çünkü Türkiye'nin doğusunda sadece bir okulda yapılmış ve kesitsel tasarımı kullanılmıştır. Gelecekteki çalışmalar için hemşirelik öğrencilerinden farklı bölgelerden rastgele örnekleme önerilmektedir. Yine öğrencilerin kadına yönelik şiddet konusunda elde edilen tutum bilgileri öğrencilerin öz bildirimine dayalı olup sadece Şi̇Ö ile sınırlıdır.

\section{Sonuç}

$\mathrm{Bu}$ çalışmada öğrencilerin şiddete yönelik puan ortalamalarının genel olarak düşük ve şiddet tutumlarının geleneksellikten az ve şiddet tutumlarının çağdaş görüşe yaklaştığı görülmektedir. Öğrencilerin cinsiyetlerinin, bölümlerinin, yaşamlarının çoğunluğunu geçirdikleri yerin, birlikte yaşanılan kişi/yerin, aile tipinin, gelir durumunun, annebaba eğitim durumunun, baba çalışma durumunun, şiddete ilişkin eğitim alma isteme durumunun, kadına yönelik şiddetle ilgili talimat ve prosedürleri isteme durumunun ve kadına yönelik şiddet olgu/şüphesini bildirmek isteme durumunun ailede kadına yönelik şiddet tutumlarını etkilediği belirlenmiştir.

Hemşirelik ve ebelik öğrencilerinin ailede kadına yönelik şiddete ilişkin tutumlarının belirlenmesinden elde edilen sonuçlar bu konudaki eğitim programlarının planlanmasında etkili olabilir. Lisans programlarının, hemşire ve ebelerin aile içi şiddet etrafındaki önemli rolünü vurgulamaları ve aile içi şiddete ilişkin klişeleşmiş kavramları ele almaları gerekir. DSÖ'nün uygulama ve politikası, şiddet konularını eğitim müfredatına (WHO, 2013) dahil etmenin önemini vurgulamaktadır; ayrıca, aile içi şiddet ile ilgili eğitimin lisans programlarının bir parçası olarak verilmesi gerektiğini belirtmektedir. Hemşirelik ve ebelik öğrencilerinin aile içi şiddet konusunda bilgi ve beceri düzeyini yükseltmek son derece önemlidir. Müfredat programında ayrı bir ders olarak açılması ve teorik eğitimin yanı sıra dersin simülasyon ve klinik eğitimi içeren uygulama becerilerinden oluşması önerilmektedir. Kongre, konferans, sempozyum gibi etkinliklerle de verilen eğitimler desteklenmeli ve sürekliliği sağlanmalıdır. İlgili derslerin ve tekrarlanan sürekli eğitimlerin farkındalığı artıracağı ve tutumlarının geliştirilmesine katkı oluşturacağı düşünülmektedir. Ayrıca araştırma sonucunda erkek 
öğrencilerin kızlara göre daha geleneksel tutum içinde olduğu belirlendiğinden bu konuda yapılacak derslere ve eğitim programlarına erkeklerin katılımının arttırılması sağlanabilir. Bunların yanında bölümlerde ve üniversitelerde konuyla ilgili bilgilendirici materyal dağıtımı ve yayınlanması uygulanabilir.

Çalışmanın ulusal düzeydeki farklı üniversitelerdeki hemşirelik ve ebelik bölümlerinin dahil edildiği daha geniş bir popülasyonda tekrar ele alınması ve geleneksel görüş ve tutuma sahip olan öğrencilerin görüş ve tutumlarının nitel yöntemlerle daha derinlemesine incelenerek nedenlerinin belirlenmesi önerilmektedir. 


\section{EXTENDED ABSTRACT}

\section{The Attitudes of Nursing and Midwifery Students toward Domestic Violence against Women

Berna Aktaş - Fadime Kaya - Nihal Bostancı Daştan

Kafkas University-Faculty of Health Science at Psychiatric Nursing Department

Although many laws, action plans and awareness studies were carried out in Turkey regarding violence against women and its reasons and prevention, this situation is very much established and became one of the most important problems carried to 21st century as an tacit problem (Baysan Arabac1, 2014; Özcan and Kırca, 2017; TUİK, 2018). According to data from the Demographic and Health Survey carried out in Turkey in 2003, it is observed that this ratio rose to $45.9 \%$ in Eastern Anatolia where the research was conducted (Şenol and Yild1z, 2013). Violence is a problem that nursing and midwifery students can see more frequently in their application areas. In addition, nursing and midwifery students are future healthcare providers and should be equipped with the basic knowledge, training and practical skills necessary to prevent, identify and better understand and manage the effects of violence (Gharaibeh, Abu-Baker and Aji, 2012). As a result of the studies carried out with nursery and midwifery students, which are a group likely to encounter women exposed to violence in our country, the level of recognizing and identifying the symptoms of violence was found to be insufficient (Tambağ and Turan, 2015; Dağlar, Bilgiç and Demirel, 2017). Determining the individual's emotions, thoughts, perceptions and attitudes towards violence is extremely important in order to fulfill the key role in handling and preventing violence.

This study was conducted cross-sectional in 2016-2017 at Kafkas University in order to evaluate the attitudes of nursing and midwifery students towards violence against women in the family and the factors affecting this. No sample was selected in the study and valid results were obtained from 522 of 859 students (60.8\%). Data were collected with a questionnaire and the Attitude Scale for Violence (ASV). In addition to 
descriptive analysis, Mann Whitney U, Kruskal Wallis tests and Spearman's rho correlation analysis were used in the data analysis.

In this study, it was determined that $39.7 \%$ of the students experienced violence (55.5\% emotional, $37.7 \%$ physical, $0.3 \%$ sexual and $6.5 \%$ economic), $43.9 \%$ witnessed violence in the family, $43.1 \%$ get training for violence in courses and $85.4 \%$ of the students wanted to have a more comprehensive education. When the scale average scores were evaluated, items were determined as Economic Violence:15.04 \pm 6.17 , Emotional, Psychological, Sexual Violence:12.90 \pm 4.88 , Legitimating Myths:5.88 \pm 2.65 , Explanatory Myths:7.03 \pm 2.53 , Total Violence Score $: 40.86 \pm 12.25$. It was seen that students'mean scores on violence were generally low, violence attitudes were less than traditional and violence attitudes were close to contemporary view. It was seen that there was a positive relationship between total violence score average and age $(\mathrm{r}=0.088 ; \mathrm{p}=0.046)$ and scale score averages of male students were higher than female students ( $U=-$ 13.603; $\mathrm{p}=0.000)$, nursery students were higher than midwifery students $(\mathrm{U}=-5.347 ; \mathrm{p}=0.000)$, those who live in villages were higher than those who live in cities $(\mathrm{U}=-2.324 ; \mathrm{p}=0.020)$ and metropolis $(\mathrm{U}=-3.408 ; \mathrm{p}=0.001)$, those who live in provinces were higher than those who live in metropolis $(\mathrm{U}=-2.314 ; \mathrm{p}=0.021)$, those who have extended $(\mathrm{U}=-2.368 ; \mathrm{p}=0.018)$ and broken families $(\mathrm{U}=-2.511 ; \mathrm{p}=0.012)$ were higher than those who have nuclear families, those who live with their friends were higher than those who live with their family $(\mathrm{U}=-3.153 ; \mathrm{p}=0.002)$ and those who live in dormitories ( $\mathrm{U}=-3.781 ; \mathrm{p}=0.000)$, those who have low income was higher than those who have high $(\mathrm{U}=-2.946 ; \mathrm{p}=0.003)$ and medium $(\mathrm{U}=-$ 2.080; $\mathrm{p}=0.038$ ) income, those whose mothers weren't literate was higher than those whose mothers graduated from elementary school $(\mathrm{U}=-$ 3.713; $\mathrm{p}=0.000)$ and high school $(\mathrm{U}=-2.032 ; \mathrm{p}=0.042)$, those whose fathers weren't working was higher than those whose fathers were working $(\mathrm{U}=-3.497 ; \mathrm{p}=0.000)$ in statistically meaningful level. It was determined that the score averages of students who don't want to receive education about violence was higher than those who want to receive education $(\mathrm{U}=-5.679$; $\mathrm{p}=0.000$ ), those who do not know or want to request instructions and procedures about violence against women was higher than those who want $\left(\chi^{2}=26.050 ; p=0.000\right)$, those who do not want to report the phenomenon/suspicion of violence against women was higher than 
those who want or want depending on the characteristics of violence $\left(\chi^{2}=58.377 ; p=0.000\right)$ in statistically meaningful level.

In this study, the opportunity to make generalization or causal inferences is limited because it was carried out in only one school in the east of Turkey and sectional design was used. For future studies, random sampling from nursing students from different regions is recommended. Again, information obtained about students'attitudes towards violence against women are based on students' self-report and is limited to AVS only. It is recommended that the students' views on domestic violence be investigated in more depth with qualitative methods and the reasons for this are determined.

\section{Kaynakça / References}

Agrawal, S., ve Banerjee, A. (2010). Perception of violence against women among future health professionals in an Industrial Township. Ind Psychiatry J, 19(2), 90-93.

Akkuş, S., ve Yıldırım, Ş. (2018). Erkeklerin kadına yönelik fiziksel şiddet uygulamasına etki eden faktörlerin incelenmesi. Gaziantep University Journal of Social Sciences, 17(4), 1368-1388.

Akyurt, Ö., Sarı, Ö.N. ve Şahin, N. (2008). Aile içi şiddette sağlık çalışanlarının rolü. I. Kadın Sağhlğı Kongresi Kitabı, Ankara, 2008.

Atasoy, I. (2017). Ebelik bölümü öğrencilerinin kadına yönelik şiddet konusundaki yaklaşımları, görüş ve deneyimlerinin belirlenmesi. Sağlık ve Toplum, 27(2), 54-63.

Baysan-Arabac1, L. (2014). Ruh sağllğı için tehdit: Şiddet. (Ed. O. Çam, E. Engin) Ruh Sağlığı ve Hastalıkları Hemşireliği Bakım Sanatı içinde (s. 803-824), İstanbul:Tip Kitapevi,.

Bozkurt, Ö.D., Daşıkan, Z., Kavlak, O. ve Şirin, A. (2013). Ebelik Öğrencilerinin gebelikte şiddet konusundaki bilgi, görüş ve mesleki tutumlarının belirlenmesi. Balıkesir Sağlık Bilimleri Dergisi, 2(2), 99-107.

Bradbury-Jones, C., ve Broadhurst, K. (2015). Are we failing to prepare nursing and midwifery students to deal with domestic abuse? Findings from a qualitative study. Journal of Advanced Nursing, 71(9), 20622072. 
Cavanaugh, C., Campbell, J., Whitt, V., ve Wingood, G. (2019). Pilot test of an adapted, evidence-based intervention for preventing HIV for women residing in domestic violence shelters. Violence Against Women, 1077801219838329.

Connor, P. D., Nouer, S. S., Speck, P. M., Mackey, S. N., ve Tipton, N. G. (2013). Nursing students and intimate partner violence education: improving and integrating knowledge into health care curricula. Journal of Professional Nursing, 29(4), 233-239.

Çelik, A. S., Türkoğlu, N., Apay, S. E., Aydın, A., ve Pasinlioğlu, T. (2015). Ebe ve hemşirelere verilen eğitimin kadına yönelik aile içi şiddete ilişkin tutumlarına etkisi. Sağlık Bilimleri Meslekleri ve Dergisi, 2(2), 138-148.

Çıtak-Tunç, G., Çıtak-Bilgin, N. ve Kılınç, F. E. (2018). Awareness level of nursing students regarding violence against women - example from Turkey, International Journal of Eurasia Social Sciences, 9(33), 16051622.

Dağlar, G., Bilgic, D., ve Demirel, G. (2017). Ebelik ve hemşirelik öğrencilerinin kadına yönelik şiddete ilişkin tutumları. Dokuz Eylül Üniversitesi Hemşirelik Fakültesi Elektronik Dergisi, 10(4), 220-228.

Del Río Ferres, E., Megías, J. L., ve Expósito, F. (2013). Gender-based violence against women with visual and physical disabilities. Psicothema, 25(1), 67-72.

Delara, M. (2016). Mental health consequences and risk factors of physical intimate partner violence. Mental Health Fam Med., 12, 119-125.

Doran, F., ve Hutchinson, M. (2017). Student nurses' knowledge and attitudes towards domestic violence: results of survey highlight need for continued attention to undergraduate curriculum. J Clin Nurs., 26(15-16), 2286-2296.

Elmalı, F., Kaya Erten, Z., Zincir, H., Özen, B. ve Balcı, E. (2011). Hemşire ve ebelerin aile içi fiziksel şiddete bakış açıları maruziyetleri. Sağlık Bilimleri Dergisi, 20(1),39-47.

Er Güneri, S.E. (2016). Üniversite öğrencilerinin kadına uygulanan şiddete yönelik tutumlarının belirlenmesi. Turkiye Klinikleri ObstetricWomen's Health and Diseases Nursing-Special Topics, 2(2), 49-56.

Gharaibeh, M. K., Abu-Baker, N. N., ve Aji, S. (2012). Attitudes toward and justification for wife abuse among Syrian medical and nursing students. J Transcult Nurs, 23(3), 297-305. 
Gonzalez-Guarda, R. M., Williams, J. R., Williams, W., Lorenzo, D., ve Carrington, C. (2019). Determinants of HIV and sexually transmitted infection testing and acquisition among female victims of intimate partner violence. J Interpers Violence. doi: 10.1177/0886260519827662

Gömbül, Ö. (2000). Hemşirelerin ailede kadına eşi tarafından uygulanan şiddete ve şiddete mesleki role ilişkin tutumları. Hemşirelikte Araştırma Geliştirme Dergisi, 2(1), 19-32.

Hawcroft, C., Hughes, R., Shaheen, A., Usta, J., Elkadi, H., Dalton, T.,Ginwalla, K., ve Feder, G. (2019). Prevalence and health outcomes of domestic violence amongst clinical populations in Arab countries: a systematic review and meta-analysis. BMC public health, 19(1), 315.

Kanbay, Y., Işık, E., Yavuzaslan, M., ve Keleş, S. (2012). Hemşirelik öğrencilerinin kadına yönelik aile içi şiddetle ilgili görüş ve tutumlarının belirlenmesi. Gümüşhane Üniversitesi Sağlık Bilimleri Dergisi, 1(2), 107119.

Kaplan, S., Akalın, A., Pınar, G., ve Yılmazer, T. (2014). Hemşirelik öğrencilerinin kadına yönelik aile içi şiddete ve mesleki rollerine yönelik tutumları. Yıldırım Beyazıt Üniversitesi Sağlık Bilimleri Dergisi, 2(1), 2635.

Karabulutlu, Ö. (2015). Hemşirelik öğrencilerinin kadına yönelik aile içi şiddete ilişkin deneyimleri ve tutumları. Cumhuriyet Hemşirelik Dergisi, 4(1), 27-34.

Karakurt, G., Smith, D., ve Whiting, J. (2014). Impact of intimate partner violence on women's mental health. J Fam Violence., 29(7), 693-702.

Kodan Çetinkaya, S. (2013). Üniversite öğrencilerinin şiddet eğilimlerinin ve toplumsal cinsiyet rollerine ilişkin tutumlarının incelenmesi. Nesne Psikoloji Dergisi, 1(2),21-43.

Kurt, E., Küpeli, N. Y., Sönmez, E., Bulut, N. S., ve Akvardar, Y. (2018). Domestic violence among women attending to psychiatric outpatient clinic. Noro Psychiatry Ars., 55(1), 22-28.

Mermer, G. ve Öztürk-Dönmez, R. (2018). Nursing students' attitudes towards violence against women and professional role in violence. Researcher: Social Science Studies, 6(4),129-143.

Natan, M. B., Khater, M., Ighbariyea, R., ve Herbet, H. (2016). Readiness of nursing students to screen women for domestic violence. Nurse education today, 44, 98-102. 
Ortabag, T., Ozdemir, S., Bebis, H., ve Ceylan, S. (2014). Perspectives of young adult men regarding VAW: A cross-sectional study from Turkey. J Fam Violence., 29(6), 665-674.

Özcan, Ş., ve Kırca, N. (2017). Çözülemeyen sorun: kadına yönelik aile içi şiddet ve hemşirenin rolü. Balıkesir Sağllk Bilimleri Dergisi, 6(2), 87-96.

Paulin Baraldi, A. C., de Almeida, A. M., Perdoná, G., Vieira, E. M., ve dos Santos, M. A. (2013). Perception and attitudes of physicians and nurses about violence against women. Nurs Res Prac., vol. 2013, doi: $10.1155 / 2013 / 785025$.

Ramsay, J., Rutterford, C., Gregory, A., Dunne, D., Eldridge, S., Sharp, D. ve Feder, G. ( 2012). Domestic violence: knowledge, attitudes, and clinical practice of selected UK primary healthcare clinicians. $\mathrm{Br} J$ Gen Prac., 62(602), 647-655.

Sabancıoğulları, S., Taşkın Yılmaz, F., Ar, E., ve Çakmaktepe, G. (2016). Hemşirelik öğrencilerinin kadına yönelik şiddete ve şiddette mesleki role ilişkin tutumları, benlik saygıları ve etkileyen faktörler. Hemşirelikte Eğitim ve Araştırma Dergisi, 13(1), 35-43.

Speizer, I.S. (2010). Intimate partner violence attitudes and experience among women and men in Uganda. J Interpers Violence., 25(7), 12241241.

Sprague, S., Kaloty, R., Madden, K., Dosanjh, S., Mathews, D.J., ve Bhandari, M. ( 2013). Perceptions of intimate partner violence: a cross sectional survey of surgical residents and medical students. J Inj Violence Res. 5(1), 1-10.

T.C. Aile ve Sosyal Politikalar Bakanlığı. (2015). Türkiye'de kadına yönelik aile içi şiddet araştırması. Ankara:Elma Teknik Basım ve Matbaacılık, 11.04.2018 tarihinde http://www.hips.hacettepe.edu.tr/KKSATRAnaRaporKitap26Mart.pdf adresinden erişilimiştir.

Tambağ, H., ve Turan, Z. (2015). Ability of nursing students to recognize signs of violence against women. International J Nurs Knowl, 26(3), 107-112.

Taşdemir-Afşar, S. (2015). Türkiye'de şiddetin "kadın yüzü". Journal of Sociological Studies/Sosyoloji Konferanslari, 52(2015-2), 715-753.

Türkiye İstatistik Kurumu (TÜIK) Yillara ve cinsiyete göre illilçe merkezleri ve belde/köyler nüfusu:1927-2018, 11.04.2018 tarihinde http://www.tuik.gov.tr/UstMenu.do?metod=temelist adresinden erişilmiştir. 
Uyar, M., Yıldırım Öztürk, E.N. ve Şahin, T.K.(2018). Kadına yönelik şiddete genel bir bakış. The Journal of Academic Social Science, 6(71), 154-162.

Watts, C., ve Mayhew, S. (2004). Reproductive health services and intimate partner violence: shaping a pragmatic response in Sub-Saharan Africa. International Family Planning Perspectives, 30(4), 207-213.

World Health Organization. (2013). Responding to intimate partner violence and sexual violence against women: Clinical and policy recommendations. 10.04.2019 tarihinde http://www.who.int/reproductivehealth/publications/_ violence/ 9789241548595/en/ adresinden erişilmiştir.

World Health Organization (2017). Violence against women. 10.04.2019 tarihinde https://www.who.int/en/news-room/factsheets/detail/violence-against-women adresinden erişilmiştir.

\section{Kaynakça Bilgisi / Citation Information}

Aktaş, B., Kaya, F. ve Bostancı-Daştan, N. (2019). Hemşirelik ve ebelik öğrencilerinin ailede kadına yönelik şiddete ilişkin tutumları. OPUS-Uluslararası Toplum Araştırmaları Dergisi , 14(20), 14481474. DOI: $10.26466 /$ opus. 611843 